\title{
Onze wreedheden, onze opstanden. Slavernijgeschiedenis als vaderlandse geschiedenis
}

\author{
Markha Valenta*
}

'Ik strijd om weer mens te zijn' Tula Rigaud (1795)

\begin{abstract}
De totstandkoming van mijn geboorteland - de Verenigde Staten - bestond voor een belangrijk gedeelte uit een wrede confrontatie tussen volkeren van drie werelddelen: inheemse indianen, Afrikanen en Europeanen. Binnen de VS wordt de nationale geschiedenis dan ook begrepen als iets wat fundamenteel gevormd is door Europese ideeën, culturen en politiek. Die invloed is terug te zien in de verwezenlijking van de VS als moderne democratie en wereldmacht, maar ook in de raciale hiërarchieën die leidden tot een genocide op indianen en een buitengewoon wrede vorm van slavernij. Tot op de dag van vandaag worstelen we met de vraag hoe deze geschiedenis te herdenken en hoe om te gaan met de blijvende sporen van geweld uit het verleden. Dit geweld wordt niet alleen beschouwd als kenmerkend voor de VS, maar ook als een erfenis die 'Europa' aan de nieuwe wereld naliet.

Europa zelf lijkt echter vrij weinig belangstelling te hebben voor deze geschiedenis en nalatenschap. Toen ik als Amerikaanse immigrant naar Nederland kwam, viel het mij op hoe ongemakkelijk de stilte rondom het onderwerp van de slavernij was, hoe zeer men geneigd was om de wreedheid ervan te bagatelliseren en de contemporaine weerstand ertegen weg te wuiven. Alsof de Nederlandse handel in slaafgemaakten uitsluitend een zakelijke - en tijdelijke - aangelegenheid was geweest, waartegen pas veel later weerstand ontstond: eerst geweld, gevolgd door verlichting. Maar eigenlijk was het natuurlijk andersom: eerst de Verlichting en pas daarna de Atlantische slaveneconomie. Dit artikel is de uitkomst van mijn eigen worsteling als 'Nederlander in wording' met zulke nationale verschillen in herinneringscultuur en geschiedschrijving. ${ }^{1}$ Het is een pleidooi om slavernij - en de opstanden ertegen - als wezenlijk onderdeel van ons collectieve nationaal verleden te erkennen.
\end{abstract}

Een van de meest opvallende aspecten van de publieke omgang met het slavernijverleden is de grote afstand die veel Nederlanders voelen tot dat verleden. In de

* Dr. Markha Valenta is trans-Atlantisch wetenschapper op het gebied van vraagstukken rond globalisering en politiek. Haar onderzoek richt zich met name op Nederland, de Verenigde Staten en India, met nadruk op de wisselwerking tussen internationale en lokale conflicten rond religie, ras en burgerschap. Kernvraag hierbij is hoe globalisering de natiestaat (nationale identiteit, politiek en rechtssystemen) onder druk zet en alternatieven daarop mogelijk maakt. Ze werkt aan de Radboud Universiteit Nijmegen, schrijft voor openDemocracy en doet regelmatig mee aan publieke debatten. 
afgelopen jaren zagen we een aantal boeiende documentaires, tentoonstellingen, monumenten, herdenkingen, lespakketten, stedelijke rondleidingen, informatieve websites en debatten langskomen over een thema dat eerder schitterde door afwezigheid in verhouding tot de discussies erover in het buitenland. Het feit dat dit thema langzaamaan zichtbaar en bespreekbaar aan het worden is, wekt echter de nodige tegenreacties op bij degenen die deze groeiende aandacht afdoen als politieke correctheid, overdreven slachtofferschap en een ondermijning van onze nationale samenhorigheid. Het remmende effect van zulke reacties is duidelijk. Ondanks de groeiende, publieke, tastbare aanwezigheid van de slavernijgeschiedenis heeft dit zich tot nu toe nauwelijks vertaald in een brede mate aan empathische internalisering ervan. Voor de meeste Nederlanders blijft slavernij hardnekkig iets van 'hen' en niet van 'ons'; iets van 'toen en daar', ver van het hier en nu.

Het vertalen van de nieuwste wetenschappelijke ontdekkingen voor een breed publiek vergt meer dan creatieve vormen, gevarieerde podia en formidabele instituten. De grootste uitdaging ligt erin om duidelijk te maken hoe dit zich verhoudt tot de cultuurstrijd van deze tijd, waarin sommigen de wetenschap an sich ter discussie stellen (zowel publiek als politiek), vooral als ze van mening zijn dat deze een bedreiging vormt voor geliefde nationale rituelen, mythes en identiteiten. Het debat rondom de slavernijgeschiedenis maakt zichtbaar dat Nederland is overgegaan van een multicultureel wereldimperium naar een multinationale, multiculturele staat. We zijn nu een samenleving waarin de nakomelingen van voormalige slaafgemaakten en andere slachtoffers van de koloniale uitbuiting samenwonen met nakomelingen van degenen die daarvan hebben geprofiteerd (inclusief de Nederlandse samenleving als geheel).

Dit benoemen kan heftige weerstand oproepen. De slavernijgeschiedenis roept vragen op over nationale identiteit en nationale zelfdeceptie, over het onverlichte van de Verlichting, over de verhouding tussen de moderne economie en geweld, en over de halsstarrigheid waarmee we als samenleving ongelijkheid tolereren en in stand houden. Die vragen zijn pijnlijk. Juist door ons met deze vragen bezig te houden, kunnen we echter de middelen in handen krijgen - individueel en collectief - om een ander soort samenleving te creëren: een samenleving die recht doet aan de geschiedenis van al haar burgers vanuit een gedeelde solidariteit.

Hoe lastig dit kan zijn, zien we terug in de omgang met nationale symbolen. Zo reed tot voor kort de gouden koets op Prinsjesdag onbekommerd door de straten van Den Haag met op haar zijkant een sierlijke verbeelding van halfnaakte onderdanen die de witte Nederlandse Maagd eren. Kritiek hierop werd veelal afgedaan als politiek correct presentisme dat erop uit was om de geschiedenis te veranderen. Toen in 2016 werd begonnen met de renovatie van de koets, werd het idee opnieuw geopperd - in 2011 al eens voorgesteld door (onder anderen) Kamerleden Harry van Bommel (SP) en Mariko Peters (GL) - om dat paneel van de koets te vervangen. Het antwoord van premier Rutte hierop was onomwonden: 'Onzin, we gaan de gouden koets niet vernielen en de geschiedenis kun je niet herschrijven.'

Het paneel toont natuurlijk sowieso al een vertekening van de geschiedenis. Het is een mythische idealisering van kolonialisme en slavernij, waarbij esthetiek wordt toegepast om uitbuiting, moord en wreedheid om te toveren tot vreedzame 
overheersing. Aandacht vragen voor de slavernijgeschiedenis is niet zozeer een roep om de geschiedenis te herschrijven, maar om die eindelijk eens in het publieke domein zonder verbloeming en bagatellisering weer te geven.

Een paneel met een ontmythologiseerde weergave van de geschiedenis zou er heel anders uitzien. Stel je voor hoe het zou zijn als het gewraakte paneel vervangen zou worden door een van de etsen uit het boek van John Gabriel Stedman. Deze Schotse Nederlander reisde op het hoogtepunt van de Verlichting naar Suriname (1772-1777) en deed daar beeldend verslag van. De gedrukte versie hiervan werd geillustreerd met etsen van de beroemde dichter William Blake en anderen (Stedman, 2016 [1796]). De koets zou van een van die etsen kunnen worden voorzien. Als we hiervoor de meest bekende zouden gebruiken, dan zouden we - terwijl de koets deftig voorbij rolt - een slaafgemaakte man te zien krijgen die voor straf is opgehangen aan een haak die via een snee aan zijn ribben is bevestigd, druipend van het bloed. Stedman schreef dat de man die in deze ets wordt afgebeeld nog drie dagen voortleefde, het water drinkend dat over zijn borst sijpelde, totdat een bewaker uit medelijden zijn hersenen met een geweer insloeg. De bedoeling van deze en soortgelijke straffen, legde Stedman uit, was om de marteling en het sterfproces zolang mogelijk te rekken. Deze straffen waren niet buitengewoon, maar juist gewoon. De bewuste bedoeling hiervan was om het afschrikeffect op slaafgemaakten te vergroten.

Een overzicht van de martel- en straftuigen die werden gebruikt op de slavenplantages van de nieuwe wereld toont de menselijke creativiteit van haar meest duivelse kant. Een alternatief paneel voor de gouden koets - opnieuw met oog voor levensechtheid in plaats van verhulling - zou ook kunnen putten uit een van de schaarse dagboeken uit die tijd, dat van ene Thomas Thistlewood, een plantageeigenaar in Jamaica waar de omstandigheden vergelijkbaar waren met die in Suriname. Hij schrijft in detail over zijn jarenlange pogingen om gehoorzaamheid af te dwingen (Burnard, 2004). Zo vertelt hij bijvoorbeeld dat hij een man met de naam Port Royal betrapt had op het eten van suikerriet. Eerst ranselde Thistlewood hem af met een zweep en daarna wreef hij zout in de wonden. Vervolgens liet hij de man zijn mond openhouden terwijl een andere slaafgemaakte zich daarin ontlastte, waarna Port Royals mond urenlang werd dicht gepropt met een knevel. Andere slaafgemaakten op de Thistlewood-plantage werden gebrandmerkt in hun gezicht, er werd in hun mond en ogen gepiest. Ze werden verkracht, of ze moesten maandenlang met zware ijzers om hun nek lopen.

Slaafgemaakten werden juridisch tot werkgoed, vastgoed en object verklaard. Soms wordt gesteld dat dit begrepen moet worden 'in de eigen termen' van die tijd en dat deze vorm van slavernij simpelweg een voortzetting was van praktijken die teruggaan tot de klassieke oudheid. De historicus Piet Emmer - auteur van het bestverkochte boek over de Nederlandse bijdrage aan de trans-Atlantische slavenhandel - is een van de bekendste voorstanders hiervan (Emmer, 2003, 2018). Zijn argumenten zijn wijdverbreid in het debat en op publieke fora.

Er is echter opvallend weinig aandacht voor de manier waarop de heersende 'termen' en normen ook in de tijd van de slavernij al onderhevig waren aan onenigheid, conflict en politieke strijd. Voor een deel was dit omdat de slavernij op de plantages juist een breuk vormde met historische ontwikkelingen. In de Middel- 
eeuwen was slavernij in West-Europa immers al afgeschaft. Wat West-Europa betrof moest slavernij in de vroegmoderne tijd dus opnieuw worden 'uitgevonden', nu ten dienste van een ontluikend kapitalistisch systeem. De nieuwe vorm van slavernij die zich op de plantages ontwikkelde, was sui generis in het structureel toepassen van vernedering, verkrachting, marteling en onderdrukking op een industriële schaal. In de loop van de tijd leidde dit tot het ontstaan van 'ras' als een aparte sociaaleconomische, culturele, juridische en wetenschappelijke categorie (Degler, 1959; Jordan, 1968; Parent, 2003; Coombs, 2011; Curran, 2011; Roberts, 2016). Die combinatie - van wrede slavernij als de basis van een heel socio-economisch stelsel, genormaliseerd door een alomvattende ideologie van raciaal verschil - wordt in de Angelsaksische wereld aangeduid als rassenslavernij ('racial slavery'). De rassenslavernij op de plantages - ten dienste van de productie voor een wereldmarkt - was een uitvinding van een unieke variant van barbaarsheid in de westerse moderniteit die de drijvende motor vormde voor het opbloeien van de Atlantische wereld (Du Bois, 1920; Robinson, 1983; Kelley, 2017). Onze nationale rijkdom in het heden, als trans-Atlantisch handelsland, berust nog steeds voor een belangrijk deel op de vruchten hiervan (Williams, 1994 [1944]; Solow \& Engerman, 1987; Van Rossum \& Fatah-Black, 2012; Beckert \& Rockman, 2016).

De spanning tussen de idealen van de Verlichting en de brute realiteit van de slavernij bleef niet onopgemerkt, zowel door witte mensen als door slaafgemaakten. $\mathrm{Al}$ vroeg in de achttiende eeuw werd rassenslavernij ter discussie gesteld. In de recente biografie van Benjamin Lay (1682-1759) door de sociale historicus Markus Rediker wordt hiervan een bijzonder voorbeeld gegeven (Rediker, 2017). Lay was een 'kleine' man, iets langer dan een meter, met een gebogen rug, een groot hoofd en dunne beentjes. Tot nu toe werd hij door historici die zich met het abolitionisme bezighielden altijd afgedaan als een ludieke figuur. De biografie van Rediker herstelt Lay echter in ere als een man die zijn tijd ver vooruit was: een radicale abolitionist die geen (geweldloos) middel schuwde om zijn mede-quakers op te roepen om hun principes na te leven. Daarnaast was hij een feminist, veganist, voorvechter van dierenrechten en een milieubewuste minimalist die in een grot woonde die hij tot een knus huis had omgebouwd.

Lay verbleef in 1718 achttien maanden lang op het Caraïbische eiland Barbados. De brutaliteit van het slavernijregime dat hij daar aantrof, was zo afgrijselijk dat hij de rest van zijn leven vol vuur zou vechten, om te beginnen onder de quakers, voor de erkenning van de menselijkheid van slaafgemaakten en de onmiddellijke afschaffing van de slavernij. Lay was fel, onverschrokken en creatief. Hij genoot brede bekendheid (en beruchtheid). Zijn eerste boek werd door niemand minder dan Benjamin Franklin gedrukt, en de vrouw van Franklin liet een portret van hem maken. Lay werd in eerste instantie door de quakers afgewezen als te radicaal, wat leidde tot het verlies van zijn lidmaatschap van verschillende religieuze genootschappen. Tegen de tijd dat hij overleed, in 1759, waren de quakers echter al goed op weg om de slavernij in eigen kring af te schaffen. Ze zouden daarna een uitermate belangrijke rol gaan spelen in het abolitionisme, niet slechts in de Engelstalige gebieden, maar over de hele wereld. 
Verhalen zoals die over Lay maken duidelijk dat er wel degelijk contemporaine weerstand bestond tegen de ontwikkeling en institutionalisering van rassenslavernij. Het moreel veroordelen van rassenslavernij komt niet alleen voort uit hedendaagse ideeën over mensenrechten, maar kent een lange geschiedenis. Waarom er op een gegeven moment voldoende momentum was om de slavernij af te schaffen blijft lastig te beantwoorden. Het zichtbaar maken van de strijd en tegenstrijdigheden in het verleden doet echter meer recht aan dat verleden in de eigen termen' dan een quasi-mythische publieke weergave van de geschiedenis of een relativerende geschiedschrijving doorspekt met blinde vlekken. Het is de moeite waard om dit aan een groot publiek duidelijk te maken.

Bovendien wordt door het zichtbaar maken van conflicten rond slavernij de lijn van het verleden naar het heden zichtbaar. Hoewel rassenslavernij als juridische, sociale en economische institutie in de negentiende eeuw werd afgeschaft, worden we nog steeds geconfronteerd met het geweld van een economisch systeem dat berust op ongelijkheid en uitbuiting, hetgeen faliekant ingaat tegen principes van gelijkheid, vrijheid en democratie. Hierdoor blijft ras - hoewel al lang wetenschappelijk failliet verklaart - voortbestaan in het heden als een categorie die socioculturele verschillen vervlecht met economische ongelijkheid.

De felheid waarmee de strijd voor en tegen rassenslavernij werd bevochten, had alles te maken met de behoorlijk economische belangen die op het spel stonden. Diezelfde belangen spelen ook een rol bij actuele vraagstukken, waarbij de belangen wederom oog in oog met de menselijkheid staan. Iets wat op het eerste gezicht weinig van doen heeft met de slavernijgeschiedenis - zoals klimaatverandering - kan zo onderdeel blijken te zijn van een overkoepelde kwestie. Het is bijzonder belangrijk om zulke historische, sociale en economische dwarsverbanden op een creatieve en genuanceerde manier te agenderen in het publieke domein.

Een paar jaar na het overlijden van Benjamin Lay werd in Suriname de verzetsstrijder Boni - kind van een Afrikaanse slaafgemaakte en een Nederlandse slaveneigenaar - benoemd tot leider van een groep marrons die een guerrillaoorlog tegen de plantages voerde. De economische schade die zij berokkenden, hun effectieve gebruik van geweld en hun regelmatige aanvallen in de loop van tientallen jaren betekenden dat slaveneigenaren zich er maar al te goed van bewust waren dat slaafgemaakten slavernij helemaal niet normaal vonden en bereid waren om hun lijf en leven te riskeren om een alternatief mogelijk te maken.

Hoewel slavenopstanden altijd nauw verbonden waren met een specifieke, lokale context, raakten ze in toenemende mate ook ingebed in een trans-Atlantische wereld van revoluties waarin noties van vrijheid, gelijkheid en zelfbeschikking centraal stonden. De Franse Revolutie vormde een duidelijk keerpunt. Na de revolutie werd de slavernij in Haïti afgeschaft. De poging om het een aantal jaren later weer in te voeren leidde tot een dramatische opstand, mede geïnspireerd door de principes en gebeurtenissen van de Franse Revolutie. Uiteindelijk zou dit resulteren in de eerste soevereine staat in Latijns-Amerika, voor het eerst ooit onder leiding van een alliantie van voormalige slaafgemaakten en vrije zwarten. Dit had een wereldwijd effect. 
Zo leidde de slaafgemaakte Tula Rigaud op Curaçao, rond de tijd dat Gabriel Stedmans boek werd uitgegeven, een grote opstand die geïnspireerd was door de gebeurtenissen in Haïti. Tijdens onderhandelingen wist hij te vertellen dat de Bataafse Republiek nu onder Frans gezag viel. Volgens Tula betekende dit dat, net als in Haïti, ook op Curaçao de slavernij nu officieel was afgeschaft. De opstand op Curaçao werd echter neergeslagen en Tula werd ter dood veroordeeld. Hij werd op een kruis gebonden, alle botten in zijn lichaam werden gebroken - beginnend bij zijn voeten en vervolgens omhoogwerkend - en zijn gezicht werd met fakkels verbrand. Ten slotte werd zijn hoofd eraf gesneden en op een staak tentoongesteld. De uitkomst van Tula's opstand was representatief voor wat slaafgemaakten stond te wachten als ze voor hun vrijheid probeerden te strijden. Toch was deze opstand geen uitzondering. De geschiedenis kent een lange en gevarieerde reeks van weerstandsuitingen tegen uitbuiting in de moderniteit. Een van de meest spannende ontwikkelingen binnen de huidige wetenschap - in het werk van Marcus Rediker en Peter Linebaugh (2001), Julia Gaffield (2015), Julius S. Scott (2018), Karen Salt (2019) en anderen - is dan ook de toenemende aandacht voor de manier waarop en de mate waarin opstanden, revoluties en discussies over vrijheid, gelijkheid en soevereiniteit dwars door de Atlantische wereld reisden. Voor een gedeelte gebeurde dit in de laagste lagen van de samenleving. Handelsen piratenschepen waren hiervoor het vervoersmiddel bij uitstek. Mannen en vrouwen in de havensteden rondom de Atlantische Oceaan vormden een gemêleerd gezelschap waarin alle windstreken en continenten vertegenwoordig waren. Hun nauwe contact met elkaar zorgde ervoor dat er een 'ondergronds' circuit aan radicale ideeën en netwerken ontstond dat arbeiders, zeelieden, marktvrouwen, piraten, prostituees, knechten én slaven met elkaar verbond via schepen, kroegen, markten en scheepswerven. Slavernij was onder hen een onderwerp van fel debat. Dit circuit was een belangrijke voedingsbodem voor een trans-Atlantisch, zwart radicalisme dat opstanden zoals dat van Tula inspireerde. Tegelijkertijd creëerde het een indrukwekkende alternatieve wereld van sociale verhoudingen waarin raciale verschillen werden geminimaliseerd en soms zelfs verdwenen. Op deze manier is de geschiedenis van slavernij diep vervlochten met de algemene sociale geschiedenis van de moderniteit.

De invloed van radicale ideeën over vrijheid en van zwarte opstanden bleef echter niet beperkt tot de onderste lagen van de bevolking of de wereld van de plantages. Zoals Susan Buck-Morss (2009) heeft weten vast te leggen, volgde de Duitse filosoof Friedrich Hegel de ontwikkelingen in Haïti op de voet via het tijdschrift Minerva. Dit was de inspiratie voor zijn discussie over de meester-slaafdialectiek, een van de meest invloedrijke discussies in de geschiedenis van de westerse filosofie. Op deze manier kwam de historische strijd tegen rassenslavernij vanuit de Caraibische gebieden terecht in het hart van Europa. De sleutelpassages van Hegel zouden vervolgens van invloed zijn op een hele reeks denkers en doeners, van marxisten tot feministen, van Freud tot Martin Buber tot de antikoloniale Frantz Fanon.

De geschiedenis van rassenslavernij is een van de sleutels tot het begrijpen van de moderne wereld - en dus ook van Nederland en Europa. Deze geschiedenis wordt niet netjes afgebakend door culturele en raciale lijnen. Het is bovendien geen 
afgesloten hoofdstuk. De geschiedenis van de rassenslavernij is meer dan een ongekend wreed voorbeeld van langdurige onmenselijkheid ten dienste van profijt en overheersing. Het is iets van 'ons' en van 'nu'. Daarom moet er niet alleen ruimte worden gemaakt voor deze geschiedenis in onze debatten, documentaires en lespakketten, maar ook in het concrete publieke domein: in de symbolen die we gebruiken, de nationale rituelen die we bezigen, en de werken die we als waardevol beschouwen. Laten we om te beginnen het eerdergenoemde paneel op de gouden koets vervangen door een verbeelding van Boni's guerrillastrijd, Boni en Tula Rigaud als voorvechters van vrijheid en gelijkheid vieren in onze nationale verhalen, en van 5 mei een inclusieve nationale Bevrijdingsdag maken waarbij Keti Koti een even belangrijke plaats inneemt als het einde van de Tweede Wereldoorlog.

\section{Noot}

1 Met hartelijke dank aan Willem Frijhoff voor een levendig en verhelderend gesprek over de verschillen tussen Amerikaanse en Nederlandse houdingen tegenover de slavernijgeschiedenis.

\section{Literatuur}

Beckert, S., \& Rockman, S. (red.) (2016). Slavery's capitalism: A new history of American economic development. Philadelphia: University of Pennsylvania Press.

Buck-Morss, S. (2009). Hegel, Haiti, and Universal History. Pittsburgh: University of Pittsburgh Press.

Burnard, T. (2004). Mastery, tyranny, and desire: Thomas Thistlewood and his slaves in the Anglo-Jamaican world. Chapel Hill: University of North Carolina Press.

Coombs, J.C. (2011). Beyond the 'origins debate': Rethinking the rise of Virginia Slavery. In: D. Bradburn \& J.C. Coombs (red.), Early modern Virginia: Reconsidering the Old Dominion. Charlottesville: University of Virginia Press, 90-127.

Curran, A.S. (2011). The anatomy of blackness: Science and Slavery in an Age Of Enlightenment. Baltimore, MD: Johns Hopkins University Press.

Degler, C.N. (1959). Slavery and the genesis of American race prejudice. Comparative Studies in Society and History, 2 (1): 49-66.

Du Bois, W.E.B. (1920). The souls of white folk. Darkwater: Voices from Within the Veil. New York: Washington Square Press, 29-52.

Du Bois, W.E.B. (1935). Black reconstruction in America: An essay toward a history of the part which black folk played in the attempt to reconstruct democracy in America, 1860-1880. New York: Harcourt, Brace and Company.

Emmer, P.C. (2003). De Nederlandse slavenhandel 1500-1850. Amsterdam: Arbeiderspers.

Emmer, P.C. (2018). Het zwart-wit denken voorbij: een bijdrage aan de discussie over kolonialisme, slavernij en migratie. Amsterdam: Nieuw Amsterdam.

Gaffield, J. (2015). Haitian connections in the Atlantic world: Recognition after revolution. Chapel Hill: University of North Carolina Press.

Jordan, W.D. (1968). White over black: American attitudes toward the Negro, 1550-1812. Chapel Hill: University of North Carolina Press. 
Kelley, R.D.G. (2017). What is racial capitalism and why does it matter? Katz Distinguished Lecture in the Humanities and the John E. Sawyer Seminar on Capitalism and Comparative Racialization. Simpson Center for the Humanities, University of Washington. November 7, 2017. Retrieved from https://www.youtube.com/watch? $\mathrm{v}=$ REo_gHIpvJc

Parent, A.S. (2003). Foul means: The formation of a slave society in Virginia 1660-1740. Chapel Hill: University of North Carolina Press.

Rediker, M. (2017). The fearless Benjamin Lay: The Quaker dwarf who became the first revolutionary abolitionist. Boston: Beacon Press.

Rediker, M., \& Linebaugh, P. (2001). The many-headed hydra: Sailors, slaves, commoners, and the hidden history of the revolutionary Atlantic. Londen: Verso.

Roberts, J. (2016). Race and the origins of plantation slavery. Oxford Research Encyclopedias: American History. http://oxfordre.com/americanhistory/view/10.1093/acrefore/ 9780199329175.001.0001/acrefore-9780199329175-e-268 .

Robinson, C. (1983). Black Marxism: The making of the black radical tradition. London: Zed Press.

Rossum, M. van, \& Fatah-Black, K. (2012). Wat is winst? De economische impact van de Nederlandse trans-Atlantische slavenhandel. Tijdschrift voor Sociale en Economische Geschiedenis, 9 (1): 3-29.

Salt, K. (2019). The unfinished revolution: Haiti, black sovereignty and power in The 19th-century Atlantic world. Liverpool: Liverpool University Press.

Scott, J.S. (2018). The common wind: Afro-American currents in the age of the Haitian revolution. Londen: Verso.

Solow, B.L., \& Engerman, S.L. (red.) (1987). British capitalism and Caribbean slavery: The legacy of Eric Williams. Cambridge: Cambridge University Press.

Stedman, J.G. (2016 [1796]). Narrative of a five years expedition against the revolted Negroes of Surinam, from the year 1772 to 1777, elucidating the history of that country and describing its productions. Londen: Joseph Johnson.

Williams, E. (1994 [1944]). Capitalism \& slavery. Chapel Hill: University of North Carolina Press. 